\section{Liver disease and platelet function in alcoholics}

Mikhailidis et al reported that chronic alcohol ingestion exerts an inhibitory effect on platelet function even in the absence of alcohol in the blood and that this phenomenon is reversible with abstinence. Platelet aggregation and associated thromboxane formation were inhibited on admission but returned to normal or became hyperresponsive during two to three weeks of abstinence. Their data also suggested a relation between the bleeding time and estimated alcohol intake during the week preceding detoxification. ${ }^{1}$

As alcoholic cirrhosis of the liver may cause bleeding and coagulation abnormalities we decided to see whether the inhibited platelet function of alcoholics on admission for detoxification might be related to liver disease in these patients.

\section{Patients, methods, and results}

Twenty six chronic alcoholics were studied within 24 hours of admission to our inpatient detoxification department. The subjects denied taking any drugs during the week before the study and none had salicylates in the urine on the day of admission. All gave informed consent.

All had been drinking up to the day of admission and had signs and symptoms of alcohol withdrawal, for which they were given oxazepam. ${ }^{2}$ Laboratory data showed that 16 of the 26 subjects had serum transaminase activities four times higher than normal despite normal albumin and bilirubin concentrations. These subjects gave permission for liver biopsy. In 13 cases the histological appearance of liver tissue showed fatty infiltration varying from $11 \%$ to $29 \%$, whereas in three cases liver morphology was normal. Platelet function was studied as described. ${ }^{2}$

Platelet values in the 13 alcoholics with fatty liver were compared with those in the three patients with normal liver morphology. A significant correlation $(r=0.519 ; \mathrm{df}=15 ; \mathrm{p}<0.05)$ was found between the degree of fatty infiltration of the liver and the bleeding time. There was no significant correlation between bleeding time and recent ethanol intake or bleeding time and the other variables of platelet function.

Prolongation of the bleeding time was found on admission in the alcoholics with fatty liver (table). The mean difference between alcoholics with and without liver disease was $137 \mathrm{~s}(95 \%$ confidence interval 72 to $202 \mathrm{~s} ; t=4 \cdot 30, \mathrm{df}=24$, $\mathrm{p}<0.001)$. The capacity of blood to form thromboxane calculated as the product of platelet count and thromboxane $\mathbf{B}_{2}$ formed per $10^{7}$ platelets was significantly less $(t=2 \cdot 36 ; \mathrm{df}=24 ; \mathrm{p}<0.05)$ in alcoholics with fatty liver than in alcoholics without signs of liver disease.

Platelet function values and ethanol intake in chronic alcoholics with and without liver disease on admission for detoxification and in non-alcoholic healthy male volunteers. Figures are means ( $S D$ in parentheses)

\begin{tabular}{lccc}
\hline & \multicolumn{2}{c}{ Alcoholics } & \\
\cline { 2 - 3 } & $\begin{array}{c}\text { Fatty liver } \\
(\mathrm{n}=13)\end{array}$ & $\begin{array}{c}\text { Normal liver } \\
(\mathrm{n}=13)\end{array}$ & $\begin{array}{c}\text { Volunteers } \\
(\mathrm{n}=13)\end{array}$ \\
\hline Platelet count $\left(\times 10^{9} / 1\right)$ & $108(45)^{\star \star \star}$ & $113(41)^{\star \star \star}$ & $197(38)$ \\
Bleeding time $(\mathrm{s})$ & $406(101)^{\star \star \star}$ & $296(53)$ & $257(76)$ \\
Platelet aggregation $(\%)$ & $43(10)^{\star \star \star}$ & $51(17)^{\star}$ & $66(13)$ \\
Thromboxane $\mathrm{B}_{2}$ formation $(\mathrm{nmol} / \mathrm{l}$ blood) & $1 \cdot 7(1 \cdot 5)^{\star}$ & $7 \cdot 2(8 \cdot 9)$ & $5 \cdot 3(4 \cdot 7)$ \\
Ethanol intake $(\mathrm{g} / \mathrm{kg})$ day) & $3 \cdot 4(1 \cdot 1)$ & $3 \cdot 8(1 \cdot 1)$ & \\
\hline
\end{tabular}

Compared with non-alcoholic healthy volunteers: ${ }^{\star} p<0.05,{ }^{\star \star \star} p<0.001$ (Student's $t$ test).

\section{Comment}

Impaired platelet aggregation, bleeding tendency, thrombocytopenia, and defects in clotting factors are common findings in alcoholic liver disease. Liver cirrhosis is associated with arachidonate deficiency ${ }^{3}$ and decreased platelet thromboxane formation, ${ }^{4}$ but it is not known whether these occur in other types of alcoholic liver disease.

In our study alcoholics with normal liver showed diminished platelet aggregation in response to adenosine diphosphate, whereas those with fatty liver showed, in addition, prolonged bleeding time and decreased capacity of blood to form thromboxane. Bleeding time showed no significant correlation with blood thromboxane forming capacity or estimated ethanol intake during the week before admission, but a significant correlation was found between bleeding time and the degree of fatty infiltration of the liver.

These observations suggest that recent ethanol intake may influence platelet aggregation but that factors other than this and decreased platelet thromboxane formation are mainly responsible for prolongation of the bleeding time in alcoholics with fatty liver. Thromboxane release from aggregating platelets is not the main determinant of skin bleeding time. ${ }^{5}$

In an earlier study we found that during the first two weeks of abstinence a significant shortening of the bleeding time occurs concomitantly with enhanced platelet aggregation and associated thromboxane formation. ${ }^{2}$ This seems to occur irrespective of whether alcoholics have a fatty liver or not.

1 Mikhailidis DP, Jenkins WJ, Barradas MA, Jeremy JY, Dandona P. Platelet function defects in chronic alcoholism. BrMed f 1986;293:715-8.

2 Hillbom M, Muuronen A, Löwbeer C, Änggård E, Beving H, Kangasaho M. Platelet thromboxane formation and bleeding time is influenced by ethanol withdrawal but not by cigarette smoking. Thromb Haemost 1985;53:419-22.

3 Johnson SB, Gordon E, McClain C, Low G, Holman RT. Abnormal polyunsaturated fatty acid patterns of serum lipids in alcoholism and cirrhosis: arachidonic acid deficiency in cirrhosis. Proc Natl Acad Sci USA 1985;82:1815-8.

4 Davi G, Migneco G, Vigneri S, Tripi S, Scialabba A, Strano A. Platelet thromboxane production in liver cirrhosis. Prostaglandins Leukotrienes Med 1985;19:99-104.

5 Thorngren M, Shaf S, Born GVR. Thromboxane $A_{2}$ in skin-bleeding-time blood and in clotted venous blood before and after administration of acetylsalicylic acid. Lancet 1983;i:1075-8.

(Accepted 15 May 1987)

Department of Neurology, University of Helsinki, SF-00290 Helsinki, Finland M HILLBOM, MD, senior lecturer and consultant in neurology

A MUURONEN, MD, lecturer in neurology

Department of Clinical and Experimental Alcohol and Drug Addiction Research, Karolinska Institute, Stockholm, Sweden

J NEIMAN, MD, research fellow

Correspondence to: Dr Hillbom.

\section{Tobacco and end stage diabetic nephropathy}

Tobacco has attracted attention in recent years as a possible risk factor for diabetic retinopathy and nephropathy ${ }^{1-3}$ but the subject remains controversial. We have compared tobacco usage by patients with end stage diabetic nephropathy with that in a matched diabetic control group.

\section{Patients, methods, and results}

The study group comprised 22 patients referred consecutively during the past four years to the nephrology division because of end stage diabetic nephropathy. Their glomerular filtration rate was $<15 \mathrm{ml} / \mathrm{min}$ and diabetes was the only plausible cause of the renal disorder. Tobacco use was recorded retrospectively, aided by interviews of the patients or with relatives of three of the patients who died.

A control group of 22 patients with type I (insulin dependent) diabetes was obtained by selectively pairing as closely as possible each uraemic patient with one of 563 insulin treated diabetics from our special outpatient clinic. Pairing criteria were sex, age, and duration of diabetes. When a choice of controls was available we always selected the one with the longest duration of diabetes. In both groups the male to female ratio was $12: 10$ and the mean age 38 (SD 8) years. The mean duration of diabetes was 29 (SD 9) years in the control group and 27 (9) years in the uraemic group.

The time from recognition of diabetes to manifest albuminuria (dip stick) was recorded. The total consumption of tobacco was calculated as pack years ${ }^{2}$-that is, a person who had smoked 10 cigarettes daily for four years had accumulated two pack years. Case notes were reviewed for the onset of albuminuria. Present kidney function was evaluated in all the control patients by measuring creatinine clearance and daily quantitative urinary excretion of microalbumin. ${ }^{4}$

There were significantly more ${ }^{5}$ (case $v$ control; $\chi^{2}$ test, two tailed, $\mathrm{p}=0.006$ ) tobacco users in the uraemic group (21 out of 22) than among the controls ( 10 out of 22) and calculations of pack years gave a higher mean value $(9 \cdot 25$ (SD 5.73)) for the total uraemic group than for the total control group $(2 \cdot 53(4 \cdot 0))$ (Student's $t$ test $=4.409 ; p<0 \cdot 001)$. Calculated for smokers only, the respective means were

Creatinine clearance and albuminuria in 22 control diabetic users and non-users of tobacco

\begin{tabular}{lcc}
\hline & $\begin{array}{c}\text { Tobacco users } \\
(\mathrm{n}=10)\end{array}$ & $\begin{array}{c}\text { Non-users } \\
(\mathrm{n}=12)\end{array}$ \\
\hline $\begin{array}{c}\text { Creatinine clearance }\left(\mathrm{ml} / \mathrm{min} / 1 \cdot 73 \mathrm{~m}^{2}\right): \\
>85\end{array}$ & 4 & 10 \\
$64-85$ & 3 & 1 \\
$32-63$ & 3 & 1 \\
$15-31$ & 0 & 0 \\
$<15$ & 0 & 0 \\
$\begin{array}{c}\text { Albuminuria }(\mathrm{mg} / \text { day }): \\
>200\end{array}$ & 6 & 2 \\
$50-200$ & 1 & 2 \\
$<50$ & 3 & 8 \\
\hline
\end{tabular}


$9 \cdot 77(5 \cdot 20)$ and $5 \cdot 57(4 \cdot 05)(t=2 \cdot 18 ; \mathrm{p}<0 \cdot 05)$. A significant inverse correlation was found between the amount of tobacco used daily and the number of years preceding the onset of proteinuria in the uraemic patients $(n=18 ; r=0.47$; $p<0.05)$ and controls $(n=7 ; r=0.82 ; p<0.01)$. In the control group smokers more often than non-smokers had renal lesions (table).

\section{Comment}

In our series the proportion of tobacco users was not the only difference between the uraemic and control groups. The lifetime consumption of tobacco was significantly less in the controls than in the uraemic group and smoking as well as ex-smoking controls presented more signs of renal disorder than did controls who had never smoked. Smokers, whether controls or uraemic subjects, had an earlier onset of proteinuria (especially those with a large daily consumption of tobacco) than non-smokers. The duration of diabetes appeared to be of minor importance for the development of end stage diabetic nephropathy.

Several factors seem to be responsible for the evolution of diabetic angiopathy and our findings suggest that one of the most important is smoking. Tobacco use in diabetics has been proposed as a trigger for progression from background to proliferative retinopathy and also from incipient to overt nephropathy. ${ }^{13}$ Our study supports this.

1 Paetkau ME, Boyd TAS, Winship B, Grace M. Cigarette smoking and diabetic retinopathy. Diabetes 1977;26:46-9.

2 Muff Nielsen M, Hjollund E. Smoking and diabetes microangiopathy. Lancet 1978;ii:533-4. 3 Mühlhauser I, Sawicki P, Berger M. Cigarette-smoking as a risk factor for macroproteinuria and proliferative retinopathy in type I (insulin-dependent) diabetes. Diabetologia 1986;29:500-2.

4 Viberti $G$, Keen $H$. The patterns of proteinuria in diabetes mellitus. Relevance to pathogenesis and prevention of diabetic nephropathy. Diabetes 1984;33:686-92.

5 Breslow NE, Day NE. Classical methods of analysis of matched data. Statistical methods in cancer research. Vol 1. The analysis of case control studies. Lyons: WHO, International Agency for Research on Cancer, 1980:162-89. (Publ No 32.)

(Accepted 26 fune 1987)

Department of Medicine, University Hospital, S-90185 Umeå, Sweden

BERND STEGMAYR, MD, PHD, consultant nephrologist

FOLKE LITHNER, MD, PHD, clinical lecturer

Correspondence to: Dr Stegmayr.

\section{Visual analogue scores and urinary incontinence}

Visual analogue scales have been reported to be valuable in diagnosing urinary incontinence in women. Parkin and Davies, in a study of 35 incontinent women, found a distinct difference between scores in patients with detrusor instability and those in patients with genuine stress incontinence. ${ }^{1}$ We assessed this technique in a larger group of women.

\section{Patients, methods, and results}

One hundred and ten consecutive women were asked to indicate the severity of their symptoms of incontinence on a $10 \mathrm{~cm}$ analogue scale. This was done before a history was taken and before patients were examined. The mark was measured to the nearest millimetre from 0 to 100 . Urodynamic testing was then performed, which included supine and provocative cystometry and urethral pressure measurements at rest and during stress. In this study all definitions and units conform to standards proposed by the International Continence Society unless otherwise stated.

From the 110 patients seen we compared the visual analogue scores of 58 patients with a diagnosis of genuine stress incontinence with the scores of 26 patients with detrusor instability. The figure shows the results. The two groups were well matched for age and parity. The mean (SD) analogue score was 64 (23) for patients with detrusor instability and $49(23)$ for patients with genuine stress incontinence, a significant difference $(p<0.01)$, as assessed by Student's $t$ test. Despite this, however, the area of overlap was large, and we could not show any clinically useful separation of the two groups. In the group of 26 patients with detrusor instability seven $(27 \%)$ had scores of $40 \mathrm{~mm}$ or below. Of 58 patients with genuine stress incontinence, $36(62 \%)$ had scores above $40 \mathrm{~mm}$.

As part of this study we also assessed quantitative urine loss using a one hour perineal pad test. ${ }^{2}$ There was no correlation between analogue scores and urine loss measured using this technique (unpublished findings).

\section{Comment}

Visual analogue scales are important in the subjective measurement of pain. ${ }^{3}$ Their use in patients with urinary incontinence is novel, and it has been suggested that they might be useful in centres where urodynamic facilities are not available. The proposition that the scores might be used to distinguish detrusor instability and genuine stress incontinence was based on the fact that all those in the detrusor instability group scored over $40 \mathrm{~mm}$, while very few of the patients with a final diagnosis of genuine stress incontinence did so. ${ }^{1}$ We could not, however, show any clinically useful separation. Obviously, a clear separation of the two groups on the basis of the

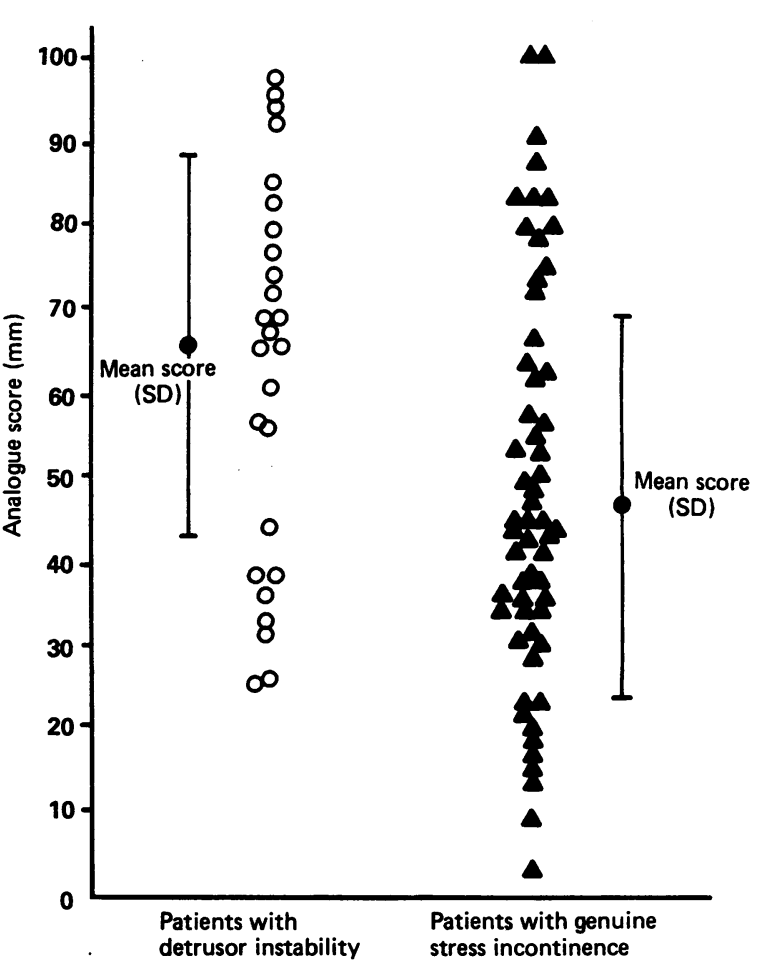

Visual analogue scores related to final diagnosis.

scores is essential if the scale is to be used as a diagnostic test. If we intend to use it as a screening procedure it should not only be inexpensive and simple to perform, which it clearly is, but also have a reasonable degree of sensitivity and specificity, which it clearly does not. We are particularly anxious about the use of such screening in patients with detrusor instability and low scores, who would be misdiagnosed as having genuine stress incontinence and treated surgically. In our study over a quarter of the group with detrusor instabilty had scores below $40 \mathrm{~mm}$.

The difference in the groups' scores does not seem to be caused by the fact that the degree of wetness is more severe in patients with detrusor instability (as assessed by the one hour pad test); it is more likely to be due to the subjective differences in the quality of the symptoms associated with the two problems or to differences in the perception of such symptoms, as it is well known that there are clear differences in the psychological profiles of the two groups. ${ }^{4}$

1 Parkin DE, Davies JA. Use of a visual analogue scale in the diagnosis of urinary incontinence. $B$ Med f 1986;293:365-6.

2 Sutherst JR, Brown $M$, Shawer $M$. Assessing the severity of urinary incontinence in women by weighing perineal pads. Lancet 1981;i:128-9.

3 Revill SI, Robinson JO, Rosen M, Hogg MIJ. The reliability of a linear analogue for evaluating pain. Anaesthesia 1976;31:1191-8.

4 Crisp A, Sutherst JR. Psychological factors in women with urinary incontinence. In: Proceedings of the International Continence Society. London: International Continence Society, 1983:174-6.

(Accepred 11 fune 1987)

Royal Liverpool Hospital, Liverpool L7 8XP

M I FRAZER, MB, MRCOG, lecturer, university department of obstetrics and gynaecology

J R SUTHERST, MD, FRCOG, reader, university department of obstetrics and gynaecology

E F N HOLLAND, MB, CHB, senior house officer in genitourinary medicine and gynaecology

Correspondence to: Dr Frazer. 